\title{
The effects of restricting enzyme supplementation in wheat-based diets to broilers
}

\author{
A.A. Figueiredo $^{a, 1}$, B.A. Correia ${ }^{a, 1}{ }$ T. Ribeiro $^{b}$, P.I.P. Ponte ${ }^{b}$, L. Falcão ${ }^{a}$, J.P. Freire ${ }^{a}$, J.A.M. \\ Prates $^{\text {b }}$, L.M.A. Ferreira ${ }^{\text {b }}$, C.M.G.A. Fontes ${ }^{\text {b,* }}$, M.M. Lordelo ${ }^{\text {a }}$ \\ a Instituto Superior de Agronomia, Tapada da Ajuda, 1349-017 Lisboa, Portugal \\ b CIISA - Faculdade de Medicina Veterinária, Pólo Universitário do Alto da Ajuda, Avenida da Universidade Técnica, 1300-477 Lisboa, Portugal
}

\section{A R T I C L E I N F O}

\section{Article history:}

Received 20 October 2010

Received in revised form

29 December 2011

Accepted 3 January 2012

\section{Keywords:}

Broiler

Enzyme

Wheat

Xylanase

\begin{abstract}
A B S T R A C T
The performance of broilers fed on xylanase supplemented diets for part or all of the production cycle was evaluated in two experiments. In a preliminary experiment, 1-day-old chicks were fed a wheat-based diet supplemented with a commercial xylanase for the entire duration of the experiment of 28 days, or during the last 21,14 , or 7 days of the trial. In experiment 2 , the growth period was extended to 36 days, and birds were fed xylanase supplemented diets for the entire duration of the experiment, or during the last 27,18 , or 9 days of the trial. In both experiments, an additional group was fed a non-supplemented control diet. Xylanase-supplemented broilers outperformed non-supplemented birds. Significant differences in body weight emerged at 21-28 days of age, suggesting that the response to xylanase supplementation occurs primarily during the latter stages of broiler growth. Broilers fed xylanase-supplemented diets for the entire experiment presented similar growth performance, intestinal viscosity, gastrointestinal enzyme activity and organ sizes when compared with birds supplemented with the exogenous xylanase for the last 14 (experiment 1 ) or the last 18 days (experiment 2 ) of the trials. Birds exposed to exogenous xylanase for the entire duration of the experiment showed, however, a non-significant trend $(\mathrm{P}<0.1)$ towards an improved final body weight and feed conversion ratio. Nevertheless, it appears that an early exposure to the exogenous xylanase is of marginal importance in obtaining a significant response to xylanase supplementation by broilers fed wheat-based diets.
\end{abstract}

(c) 2012 Elsevier B.V. All rights reserved.

\section{Introduction}

The use of exogenous enzymes in simple-stomach animal nutrition has been extensively investigated due to their role in attenuating the anti-nutritive properties of soluble non-starch polysaccharides (NSP) present in cereals. Wheat-based diets usually contain significant levels of soluble arabinoxylans, a form of NSP, which may impair feed digestion and bird performance (Steenfeldt et al., 1998; Preston et al., 2001). The addition of microbial xylanases to these diets leads to a reduction in digesta viscosity, resulting in more efficient nutrient digestion and absorption (Steenfeldt et al., 1998; Choct et al., 1999; Preston et al., 2001). As a consequence, there is an overall improvement in broiler performance as reviewed by

\footnotetext{
Abbreviations: BW, body weight; FCR, feed conversion ratio; GI, gastrointestinal; NSP, non-starch polysaccharide.

* Corresponding author at: Faculdade de Medicina Veterinária, Universidade Técnica de Lisboa, Avenida da Universidade Técnica, 1300-477 Lisboa, Portugal. Tel.: +351 21 3652876; fax: +351213652889.

E-mail address: cafontes@fmv.utl.pt (C.M.G.A. Fontes).

1 Equal contribution.
} 
Table 1

Composition and calculated analysis of the wheat-based diet used in experiments 1 and 2.

\begin{tabular}{lc}
\hline Ingredient & $\mathrm{g} / \mathrm{kg}$ of diet \\
\hline Wheat & 580.0 \\
Soybean meal, $470 \mathrm{~g} / \mathrm{kg} \mathrm{CP}$ & 165.2 \\
Soy (full-fat) & 200.0 \\
Sodium chloride & 2.5 \\
Calcium carbonate & 11.5 \\
Dicalcium phosphate & 17.3 \\
DL-Methionine & 1.5 \\
Mineral and vitamin premix ${ }^{\mathrm{b}}$ & 2.0 \\
Filler & 20.0 \\
Calculated nutrient content & \\
Metabolisable energy $(\mathrm{MJ} / \mathrm{kg})$ & 12.62 \\
Crude protein & 219.2 \\
Lysine & 11.6 \\
Methionine & 4.5 \\
Calcium & 9.2 \\
Available phosphorus & 4.4 \\
\hline
\end{tabular}

a In experiment 1 treatments consisted of a wheat-based diet supplemented with enzyme for the entire 28 days, the last 21 days, the last 14 days, the last 7 days or not supplemented. In experiment 2 treatments consisted of a wheat-based diet supplemented with enzyme for the entire 36 days, the last 27 days, the last 18 days, the last 9 days or not supplemented.

b Mineral-vitamin premix provided the following per kilogram of diet: biotin $0.5 \mathrm{mg}$, calcium pantothenate $10 \mathrm{mg}$, cholecalciferol $0.05 \mathrm{mg}$, cyanocobalamin $0.12 \mathrm{mg}$, folic acid $0.5 \mathrm{mg}$, menadione $2 \mathrm{mg}$, nicotinic acid $30 \mathrm{mg}$, pyridoxine $1.7 \mathrm{mg}$, retinol $2.7 \mathrm{mg}$, thiamin $1 \mathrm{mg}, \alpha$-tocopherol $20 \mathrm{mg}$, riboflavin, $4.2 \mathrm{mg}$, Co $0.2 \mathrm{mg}$, Cu $10 \mathrm{mg}$, Fe $80 \mathrm{mg}$, I $1 \mathrm{mg}$, Mn $100 \mathrm{mg}$, Se $0.3 \mathrm{mg}$, Zn $80 \mathrm{mg}$.

$\mathrm{c}$ The filler consisted of ground wheat. When xylanase supplementation was provided, the filler was used to mix the enzyme into the diet. When no xylanase supplementation was provided, the filler was added alone.

$\mathrm{d}$ Calculation of nutrient content based on Ingredient Analysis Table (Dale and Batal, 2009).

Bedford (2000). In addition, supplementation with exogenous enzymes allows the incorporation of alternative sources of energy that may be cheaper than corn in certain geographical areas.

Some reports indicate that chickens benefit most from enzyme addition in the grower or finishing periods, whereas others state that the benefits are more apparent at an earlier age (Dusel et al., 1998; Fontes et al., 2004; Gao et al., 2008). Fontes et al. (2004) suggested that the effects of xylanase supplementation are most prominent during the latter stages of growth, based on their study of two xylanases with different molecular architectures. Dusel et al. (1998) agreed that enzyme addition improves bird performance primarily at the end of the finishing period. Others claim that enzyme supplementation results in more pronounced improvements in growth from 7 to 21 days of age than from 22 to 49 days of age (Gao et al., 2008). In addition, Cowieson et al. (2005) demonstrated that improvements in performance occur during the starter and grower periods. It should be noted that in each of the above mentioned studies, birds were fed with enzyme supplemented diets throughout the production cycle. It is therefore difficult to disentangle the impact of supplementation at different ages.

There are logical reasons why enzyme supplementation should be beneficial to birds both young and old. In the young chick, the production of endogenous digestive enzymes is scarce and may limit feed digestion (Nitsan et al., 1991; Dunnington and Siegel, 1995). Thus, the addition of exogenous enzymes can enhance the digestive capacity of the young bird by complementing its repertoire of intestinal enzymes. As the bird ages, its digestive ability and microbiota capacity increase, and the microflora route becomes more important in mediating the beneficial effects of exogenous enzymes (Bedford, 2000).

The response to xylanase supplementation tends to be greater in older than younger broilers due to an interaction between viscosity and bacteria (Bedford and Morgan, 1996). This may result from an improved efficiency of microbial fermentation in the caecum, or through changes in caecal microbial populations. The latter effect might include a decrease in the size of detrimental microbial populations that colonise the final compartments of the gastrointestinal (GI) tract during the latter stages of the bird's growth (Apajalahti and Bedford, 1999).

Taken together the data discussed above indicate that there are several unresolved issues concerning the most effective period for diet supplementation with exogenous enzymes in cereal-based diets for broilers. In the present study, we have evaluated the impact of supplementing wheat-based diets with exogenous xylanases for the entire or for only part of the broiler production cycle, both in growth performance, intestinal viscosity and organ sizes.

\section{Materials and methods}

\subsection{Preliminary experiment (experiment 1)}

A preliminary trial was conducted from 0 to 28 days of age. One hundred and sixty one-day-old Ross 308 male broiler chicks were weighed and assigned to 40 pens of 4 birds each, such that the body weight (BW) uniformity of each pen was similar. Chicks were wing-banded for individual identification. The 40 pens were randomly assigned to 5 treatment groups consisting of a basal pelleted diet (Table 1 ) supplemented with a commercially available xylanase mixture, from Trichoderma longibrachiatum and Bacillus subtilis (Danisco Animal Nutrition, Marlborough, UK) at an inclusion rate of $0.5 \mathrm{~g} / \mathrm{kg}(\mathrm{w} / \mathrm{w}$ ), for 
the entire 28 days of the experiment (treatment A1-28), the last 21 days (treatment A7-28), the last 14 days (treatment A14-28) or the last 7 days (treatment A21-28). A fifth group was fed a basal diet without xylanase (treatment A0). The enzyme mixture was heat resistant and contained a minimum of $2500 \mathrm{U} / \mathrm{g}$ of endo- $1,4-\beta$-xylanase and $800 \mathrm{U} / \mathrm{g}$ of protease, as specified by the manufacturer (one unit of enzyme activity is the quantity of enzyme required to produce one $\mu$ mol of reducing sugar equivalent per minute). The basal diet (Table 1) contained approximately $600 \mathrm{~g} / \mathrm{kg}$ of wheat and was formulated to ensure a nutrient availability as defined by NRC (1994). Throughout the experiment, chicks were given free access to water and feed, which were provided with drinking nipples and hanging feeders, respectively. Brooders were raised in wired floor pens that were located in an environmentally controlled room adjusted daily to the recommended temperatures, according to standard brooding practices. Feed consumption and BW was determined weekly throughout the experiment, and mortality was recorded daily. Feed conversion ratio was corrected for mortality. At day 28, one bird per pen was killed by an intravenous injection of an aqueous isotonic solution of $125 \mathrm{mg}$ Thiopental (Braun, Barcelona, Spain). The empty weight of the crop, gizzard and liver, and the length of the duodenum, jejunum, ileum and caecum were measured. Digesta samples were collected from the various GI compartments to determine xylanase activity and content viscosity as described in Section 2.3.

\subsection{Experiment 2}

The protocol for this experiment was similar to experiment 1, except that 120 birds were assigned to 40 pens of 3 birds each and the duration of the trial was 36 days. The 40 pens were randomly assigned to 5 treatment groups consisting of a basal pelleted diet (Table 1) supplemented with the same xylanase mixture at a $0.5 \mathrm{~g} / \mathrm{kg}(\mathrm{w} / \mathrm{w})$ inclusion rate for the entire 36 days (treatment B1-36), the last 27 days (treatment B9-36), the last 18 days (treatment B18-36) or the last 9 days of the experiment (treatment B27-36). One group was fed a non-supplemented basal diet (treatment B0). Performance was measured as described previously. At the end of the experimental period, one bird per pen was killed to measure the size of the various GI compartments and to collect digesta samples for the analysis of xylanase activity and viscosity.

\subsection{Analytical procedures}

Prior to the detection of xylanase activity, digesta samples were centrifuged at $13,000 \times g$ for 10 min at $4{ }^{\circ} \mathrm{C}$ and the supernatant was collected for analysis. Qualitative analysis of xylanase activity in GI contents was performed in agar plates using purified wheat arabinoxylan (Megazyme, Wicklow, Ireland) at a $0.1 \%(\mathrm{w} / \mathrm{v}$ ) final concentration, in $10 \mathrm{mM}$ Tris- $\mathrm{HCl} \mathrm{pH}$ 7.0. Catalytic activity was detected after a $16 \mathrm{~h}$ incubation period at $37^{\circ} \mathrm{C}$ through the Congo Red assay plate, as described by Ponte et al. (2004) and Mourão et al. (2006).

Prior to measuring the viscosity of wheat, $15 \mathrm{~g}$ of the cereal was grounded through a $1 \mathrm{~mm}$ sieve, to which $15 \mathrm{~mL}$ of a $50 \mathrm{mM}$ Phosphate buffer solution, $\mathrm{pH} 7.0$, was added and centrifuged for $10 \mathrm{~min}$ at $10,867 \times g$. The supernatant was then removed to an eppendorf tube, placed in a water bath for $30 \mathrm{~min}$ at $40{ }^{\circ} \mathrm{C}$ and centrifuged for $5 \mathrm{~min}$ at $3354 \times \mathrm{g}$. Viscosity was then measured at $6 \mathrm{rpm}$ using a viscometer (Model LVDVCP-II, Brookfield Engineering Laboratories, Middleboro, MA) with a cup maintained at $24^{\circ} \mathrm{C}$, as described by Ribeiro et al. (2011).

To measure the viscosity of small intestine contents, samples were collected from the duodenum plus jejunum and ileum. Samples were centrifuged for $10 \mathrm{~min}$ at $10,867 \times \mathrm{g}$ and the viscosity of the sample supernatant was measured at $6 \mathrm{rpm}$ using a viscometer with a cup maintained at $24^{\circ} \mathrm{C}$.

\subsection{Statistical analysis}

Data related to bird performance from each experiment were subjected to ANOVA according to the general linear models procedure of SAS (SAS Institute, 2001). The Least Squared Means procedure was used to detect significant differences between treatment groups in a set of contrasts. Differences were considered significant when $\mathrm{P}<0.05$.

\section{Results}

\subsection{Preliminary experiment (experiment 1)}

Birds fed the diet supplemented with xylanases throughout the experimental period $(\mathrm{A} 1-28)$ were heavier $(\mathrm{P}<0.05)$ than birds without supplementation or birds supplemented during 21-28 days (Table 2). This difference was observed both at days 21 and $28(\mathrm{P}<0.05)$. In contrast, birds fed the xylanase-supplemented diet for the last 14 (A14-28) or 21 days (A7-28) of the experiment reached a final BW that was not different from the fully (A1-28) supplemented birds (P>0.05). Feed intake was unaffected by treatment (Table 2). However, the global and last week's feed conversion rate (FCR) of birds supplemented in the last one, two, three or four weeks of the experiment was reduced $(P<0.05)$ when compared with birds fed a non-supplemented diet (Table 2 ). The mortality rate was $4.38 \%$ and not influenced (P<0.05) by dietary treatment.

The relative weight and length of the bird's GI compartments were unaffected by xylanase supplementation (Table 3 ). Digesta viscosities in the hindgut and foregut were also not different between birds fed the different diets (Table 3 ). Finally, xylanase activity was detected along the entire GI tract of most birds fed xylanase-supplemented diets. This was the case 
Table 2

Body weight, feed intake and feed conversion rate of broilers fed a wheat-based diet supplemented with enzyme in specific periods (experiment 1 ).

\begin{tabular}{|c|c|c|c|c|c|c|c|c|c|c|}
\hline & \multicolumn{6}{|c|}{ Treatment $^{\mathrm{a}}$} & \multicolumn{4}{|l|}{ Contrasts } \\
\hline & A0 & A21-28 & A14-28 & A7-28 & A1-28 & SEM & $\mathrm{A} 0$ vs $\mathrm{A} 1-28$ & A21-28 vs A1-28 & A14-28 vs A1-28 & A7-28 vs A1-28 \\
\hline \multicolumn{11}{|c|}{ Body weight (g) } \\
\hline $7 \mathrm{~d}$ & 158 & 148 & 161 & 158 & 167 & 1.57 & 0.0780 & $<0.0001$ & 0.2371 & 0.1142 \\
\hline $14 \mathrm{~d}$ & 426 & 413 & 430 & 424 & 439 & 4.23 & 0.3720 & 0.0476 & 0.5428 & 0.3574 \\
\hline $21 \mathrm{~d}$ & 759 & 758 & 788 & 781 & 828 & 7.62 & 0.0041 & 0.0029 & 0.0882 & 0.0618 \\
\hline $28 d$ & 1206 & 1225 & 1282 & 1259 & 1330 & 12.15 & 0.0009 & 0.0046 & 0.1847 & 0.0727 \\
\hline \multicolumn{11}{|c|}{ Feed intake (g) } \\
\hline $0-7 \mathrm{~d}$ & 165 & 143 & 160 & 160 & 170 & 3.71 & 0.6089 & 0.0221 & 0.3568 & 0.3403 \\
\hline $7-14 d$ & 394 & 367 & 376 & 382 & 381 & 5.17 & 0.4344 & 0.4172 & 0.7480 & 0.9463 \\
\hline $14-21 \mathrm{~d}$ & 606 & 581 & 608 & 609 & 616 & 7.18 & 0.6800 & 0.1422 & 0.7276 & 0.7559 \\
\hline $21-28 d$ & 904 & 880 & 897 & 869 & 882 & 15.18 & 0.6179 & 0.9476 & 0.7407 & 0.7601 \\
\hline $0-28 \mathrm{~d}$ & 2070 & 1972 & 2041 & 2020 & 2050 & 22.10 & 0.7856 & 0.2834 & 0.8966 & 0.6778 \\
\hline \multicolumn{11}{|c|}{ Feed conversion rate $(\mathrm{g} / \mathrm{g})$} \\
\hline $0-7 \mathrm{~d}$ & 1.46 & 1.37 & 1.37 & 1.44 & 1.39 & 0.0153 & 0.1425 & 0.7602 & 0.7067 & 0.2897 \\
\hline $7-14 d$ & 1.49 & 1.41 & 1.42 & 1.47 & 1.42 & 0.0235 & 0.8651 & 0.1949 & 0.2944 & 0.5974 \\
\hline $14-21 \mathrm{~d}$ & $1.88^{x}$ & $1.76^{x y}$ & $1.72^{\mathrm{yz}}$ & $1.71^{\mathrm{yz}}$ & $1.61^{z}$ & 0.0227 & 0.0001 & 0.0273 & 0.1213 & 0.1682 \\
\hline $21-28 d$ & $2.12^{\mathrm{x}}$ & $1.90^{\mathrm{y}}$ & $1.85^{\mathrm{y}}$ & $1.84^{\mathrm{y}}$ & $1.77^{\mathrm{y}}$ & 0.0299 & $<0.0001$ & 0.0774 & 0.2044 & 0.2747 \\
\hline $0-28 \mathrm{~d}$ & $1.73^{x}$ & $1.61^{\mathrm{y}}$ & $1.59^{y}$ & $1.62^{\mathrm{y}}$ & $1.55^{\mathrm{y}}$ & 0.0159 & 0.0002 & 0.1576 & 0.3104 & 0.1117 \\
\hline
\end{tabular}

Means in the same line with different letter superscripts $(x, y, z)$ are significantly different $(P<0.05)$.

a Treatments consisted of a wheat-based diet not supplemented (A0) or supplemented with enzyme for the last 7 days (A21-28), the last 14 days (A14-28), the last 21 days (A7-28) or the entire 28 days (A1-28).

even for birds from treatments receiving the enzyme at the later experimental stages (data not shown). Viscosity of wheat used in both experiments was 4.05 cpo.

\subsection{Experiment 2}

To investigate the effects of restricting enzyme supplementation in an extended experimental period, birds in experiment 2 were killed at day 36. Final BW was not significantly different between birds fed enzyme supplemented diets during the entire duration of the experiment (B1-36), the last 27 days (B9-36), or the last 18 days (B18-36) (Table 4). Birds supplemented throughout the experiment were heavier $(\mathrm{P}<0.05)$ than non-supplemented (B0) birds or those supplemented for the last 9 days of the experiment (B27-36) (Table 3). As observed in experiment 1, feed intake was unaffected by treatment (Table 4). Total FCR was not different $(\mathrm{P}>0.05)$ between broilers fed enzyme supplemented diets during the total duration of the experiment (B1-36) and those receiving enzyme in the last 27 days (B9-36) or the last 18 days (B18-36) of the trial

Table 3

Relative weight and length of gastrointestinal tract compartments and viscosity of digesta samples of broilers fed a wheat-based diet supplemented with enzymes in specific periods (experiments 1 and 2). ${ }^{\mathrm{a}}$

\begin{tabular}{|c|c|c|c|c|c|c|c|c|c|c|c|c|c|c|}
\hline & \multicolumn{7}{|c|}{ Experiment $1^{\mathrm{b}}$} & \multicolumn{7}{|c|}{ Experiment $2^{\mathrm{b}}$} \\
\hline & A0 & A21-28 & A14-28 & A7-28 & A1-28 & SEM & $\mathrm{P}$ & B0 & B27-36 & B18-36 & B9-36 & B1-36 & SEM & $\mathrm{P}$ \\
\hline \multicolumn{15}{|l|}{ Weight (g/kg of BW) } \\
\hline Crop & 4.2 & 3.3 & 3.4 & 3.1 & 3.0 & 0.148 & NS & 3.8 & 2.9 & 2.7 & 3.0 & 3.3 & 0.144 & NS \\
\hline Gizzard & 10.7 & 9.3 & 9.9 & 9.4 & 9.2 & 0.231 & NS & 8.5 & 8.8 & 10.0 & 9.1 & 7.8 & 0.280 & NS \\
\hline Liver & 28.1 & 30.3 & 30.9 & 28.2 & 28.8 & 0.661 & NS & 31.2 & 28.6 & 27.4 & 28.5 & 27.0 & 0.760 & NS \\
\hline \multicolumn{15}{|l|}{ Length $(\mathrm{cm} / \mathrm{kg}$ of $\mathrm{BW})$} \\
\hline Duodenum & 18.0 & 18.7 & 18.5 & 18.3 & 18.4 & 0.336 & NS & 27.4 & 27.5 & 26.3 & 27.8 & 28.4 & 0.564 & NS \\
\hline Jejunum & 46.3 & 46.9 & 51.8 & 49.1 & 46.3 & 1.171 & NS & 67.6 & 71.0 & 68.2 & 68.8 & 73.9 & 1.094 & NS \\
\hline Ileum & 49.6 & 48.8 & 49.3 & 48.7 & 46.8 & 1.137 & NS & 70.8 & 69.4 & 69.8 & 65.1 & 73.6 & 1.116 & NS \\
\hline Caecum & 13.0 & 11.9 & 12.4 & 12.5 & 12.1 & 0.264 & NS & 20.2 & 17.3 & 17.9 & 17.6 & 17.5 & 0.578 & NS \\
\hline \multicolumn{15}{|l|}{ Content viscosity $(\mathrm{cpo})^{\mathrm{c}}$} \\
\hline Duodenum + Jejunum & 4.07 & 3.55 & 3.54 & 3.55 & 3.53 & 0.122 & NS & 3.05 & 3.11 & 3.05 & 3.04 & 2.82 & 0.072 & NS \\
\hline Ileum & 6.23 & 6.18 & 5.43 & 5.09 & 5.44 & 0.284 & NS & $5.33^{x}$ & $4.53^{x y}$ & $4.36^{x y}$ & $4.84^{x y}$ & $3.90^{y}$ & 0.167 & 0.044 \\
\hline
\end{tabular}

Means in the same line with different letter superscripts $(\mathrm{x}, \mathrm{y}, \mathrm{z})$ are significantly different $(\mathrm{P}<0.05)$.

a Measurements were taken at 28 days of age in experiment 1 and 36 days in experiment 2. $N=40$.

b In experiment 1 treatments consisted of a wheat-based diet not supplemented (A0) or supplemented with enzyme for the last 7 days (A21-28), the last

14 days (A14-28), the last 21 days (A7-28) or the entire 28 days (A1-28). In experiment 2 treatments consisted of a wheat-based diet not supplemented (B0) or supplemented with enzyme for the last 9 days (B27-36) the last 18 days (B18-36), the last 27 days (B9-36), or the entire 36 days (B1-36).

c Centipoise. 
Table 4

Body weight, feed intake and feed conversion rate of broilers fed wheat-based diet supplemented with enzyme in specific periods (experiment 2).

\begin{tabular}{|c|c|c|c|c|c|c|c|c|c|c|}
\hline & \multicolumn{6}{|c|}{ Treatment $^{\mathrm{a}}$} & \multicolumn{4}{|l|}{ Contrasts } \\
\hline & B0 & B27-36 & B18-36 & B9-36 & B1-36 & SEM & B0 vs B1-36 & $\mathrm{B} 27-36$ vs B1-36 & $\mathrm{B} 18-36$ vs B1-36 & B9-36 vs B1-36 \\
\hline \multicolumn{11}{|c|}{ Body weight (g) } \\
\hline $9 \mathrm{~d}$ & 216 & 211 & 216 & 222 & 215 & 1.63 & 0.7145 & 0.6010 & 0.7630 & 0.1283 \\
\hline $18 \mathrm{~d}$ & 638 & 639 & 660 & 648 & 661 & 5.59 & 0.1974 & 0.1749 & 0.9672 & 0.4704 \\
\hline $27 d$ & 1207 & 1173 & 1248 & 1247 & 1263 & 10.92 & 0.1020 & 0.0092 & 0.6676 & 0.6509 \\
\hline $36 \mathrm{~d}$ & 1731 & 1709 & 1855 & 1862 & 1878 & 20.44 & 0.0243 & 0.0065 & 0.7117 & 0.8065 \\
\hline \multicolumn{11}{|c|}{ Feed intake (g) } \\
\hline $0-9 \mathrm{~d}$ & 218 & 223 & 216 & 218 & 218 & 2.64 & 0.9660 & 0.9773 & 0.8310 & 0.5232 \\
\hline $9-18 d$ & 623 & 620 & 635 & 620 & 629 & 6.13 & 0.7499 & 0.6459 & 0.7732 & 0.6415 \\
\hline $18-27 d$ & 1050 & 995 & 1066 & 1066 & 1076 & 13.20 & 0.5287 & 0.0558 & 0.7983 & 0.7959 \\
\hline $27-36 d$ & 1149 & 1111 & 1181 & 1164 & 1153 & 14.94 & 0.9206 & 0.3933 & 0.5734 & 0.8276 \\
\hline $0-36 \mathrm{~d}$ & 3041 & 2963 & 3091 & 3073 & 3077 & 27.93 & 0.6756 & 0.2178 & 0.8828 & 0.9629 \\
\hline \multicolumn{11}{|c|}{ Feed conversion rate $(\mathrm{g} / \mathrm{g})$} \\
\hline $0-9 d$ & 1.27 & 1.30 & 1.25 & 1.26 & 1.29 & 0.0124 & 0.5816 & 0.7894 & 0.3099 & 0.3725 \\
\hline $9-18 d$ & 1.53 & 1.47 & 1.48 & 1.48 & 1.46 & 0.0192 & 0.2580 & 0.8363 & 0.8363 & 0.7739 \\
\hline $18-27 \mathrm{~d}$ & 1.90 & 1.84 & 1.79 & 1.73 & 1.76 & 0.0222 & 0.0502 & 0.2416 & 0.5395 & 0.7539 \\
\hline $27-36 d$ & 2.13 & 2.11 & 2.02 & 1.92 & 1.80 & 0.0356 & 0.0045 & 0.0063 & 0.0525 & 0.2800 \\
\hline $0-36 \mathrm{~d}$ & 1.69 & 1.67 & 1.63 & 1.59 & 1.57 & 0.0146 & 0.0067 & 0.0183 & 0.1316 & 0.4772 \\
\hline
\end{tabular}

a Treatments consisted of a wheat-based diet not supplemented (B0) or supplemented with enzyme for the last 9 days (B27-36) the last 18 days (B18-36), the last 27 days (B9-36), or the entire 36 days (B1-36).

(Table 4). Fully supplemented birds (B1-36) showed an improved ( $\mathrm{P}<0.05)$ overall FCR than non-supplemented (B0) and birds supplemented during the last 9 days (B27-36). Mortality rate was $3.33 \%$ and not influenced $(\mathrm{P}<0.05)$ by treatment.

The weight and length of the various GI compartments relative to BW and digesta viscosities in the duodenum and jejunum were unaffected $(\mathrm{P}<0.05)$ by treatment (Table 3$)$. Viscosity in the ileum, however, was lower $(\mathrm{P}<0.05)$ in broilers supplemented throughout the experiment than in non-supplemented birds (Table 3). No differences were detected in ileum content viscosity between broilers fed enzyme-supplemented diets during the last $9,18,27$, and 36 days. As observed in experiment 1, xylanase activity was detected along the entire GI tract of most animals fed a xylanase-supplemented diet (data not shown).

\section{Discussion}

In the present study, we investigated the impact of adding exogenous xylanases at different ages on the performance of broilers fed a wheat-based diet. Birds fed a xylanase-supplemented diet throughout their life outperformed nonsupplemented birds, in terms of both BW and FCR. These broiler performance data are consistent with previous findings that microbial xylanases can improve the nutritive value of wheat-based diets for broilers (Choct et al., 1999; Preston et al., 2001; Marron et al., 2001; Steenfeldt et al., 1998; Engberg et al., 2004; Wu et al., 2004).

The primary goal of this study was to determine the stage of the production cycle at which the primary response to xylanase-supplementation occurs. Significant differences in BW between the supplemented and non-supplemented groups began to emerge as birds got older, at days 21 and 28 in the preliminary experiment, and days 27 and 36 in experiment 2 . These data are consistent with previous reports that the response to xylanase supplementation may occur primarily during the latter stages of broiler growth (Bedford and Morgan, 1996; Dusel et al., 1998).

The population of poultry's GI microflora is more prolific as the bird ages and thus in older birds, it is likely that feed enzymes influence broiler performance through an interaction with microbial populations. The action of exogenous xylanases in the latter stages of growth may be facilitated by changes in the microbial populations colonising the bird's Gl tract (Bedford, 2000). As yet, the exact mechanism behind this interaction remains to be established. One possibility is that, by actively contributing to the de-polymerisation of soluble arabinoxylans in the upper regions of the GI tract, xylanases lead to a significant change in the nutrients that are available for microbial fermentation. The change in nutrient profile results from a decrease in the percentage of structural polysaccharides and increase in the levels of available xylo-oligosaccharides, which are not attacked in the small intestine (Apajalahti and Bedford, 1999). Future studies using xylo-oligosaccharide supplementation instead of xylanase may enable elucidating this possibility.

Although the visible benefits of xylanase supplementation begin to emerge at 21-28 days of age, this does not exclude the possibility that an early exposure to microbial xylanases is beneficial. The duration of the preliminary experiment $(28$ days) was possibly too short to derive appropriate conclusions in this respect. Therefore, experiment 2 lasted for 36 days and the data revealed that birds receiving exogenous enzymes throughout of the experiment reached a similar final BW to those that received enzymes exclusively in the last 18 days. Thus, the additional early exposure to microbial xylanases (until day 18 in experiment 2) had only a marginal effect on the final BW of birds. In addition, FCR was significantly altered in 
birds receiving the exogenous enzyme throughout experiment 2 , in days 9-36 and days 18-36, when compared with birds without enzyme. Thus, in economic terms, it may be beneficial to restrict xylanase supplementation to half of the production cycle in broilers with a production cycle of 36 days.

Dietary fibre can influence the development and size of broilers' digestive organs. Diets with high levels of soluble NSP induce a considerable enlargement of some portions of the GI tract (Brenes et al., 1993), stimulating an increase in protein turnover rates, which is mainly influenced by the increase in digesta viscosity (Dänicke et al., 2000). The addition of exogenous cellulases and hemicellulases decreases digesta viscosity and therefore improves feed passage rate and nutrient absorption, which may lead to a decrease in the relative weight of the digestive tract and a possible improvement in carcass yield. In the present study however, the relative weights of crop, gizzard and liver, and relative lengths of the duodenum, jejunum, ileum and caecum did not vary significantly between treatment groups. In addition, intestinal viscosities were relatively modest and were not influenced by the addition of exogenous enzymes in either experiment. It would therefore appear that low viscosity wheat-based diets have a marginal influence on GI tract size and intestinal viscosity, which are not significantly reduced by the addition of exogenous enzymes (Low, 1989). Thus, data demonstrated ranges of digesta viscosity in the current wheat-based diets between 2.8 and $6.2 \mathrm{cpo}$, which may be too small to influence the morphology of the GI tract.

\section{Conclusion}

The current study indicates that xylanase supplementation is particularly effective during the latter stages of broiler growth. Broiler feed supplementation during the entire production cycle may not be required and may be replaced by a restricted supplementation in the last half of the production period for broilers with a production cycle of 36 days. These observations may be of significant importance to commercial feed manufacturers and poultry producers. However, response to enzyme restriction when other exogenous enzymes and cereal-based diets are used remains to be investigated.

\section{Acknowledgements}

We thank Sociedade Agrícola da Quinta da Freiria SA for supplying the 1-day-old chicks and Reagro for providing the feed ingredients used in these experiments and Dave Pritchett and M. Neil Redford for the contribution editing this article. This work was supported by Fundação para a Ciência e a Tecnologia, Lisbon, Portugal (grant PTDC/CVT/103942/2008). T. Ribeiro and P. I. P. Ponte were supported by Fundação para a Ciência e Tecnologia through grants SFRH/BD/32321/2006 and SFRH/BD/17969/2004, respectively.

\section{References}

Apajalahti, J., Bedford, M.R., 1999. Improve bird performance by feeding its microflora. World's Poult. Sci. J. 15, 20-23.

Bedford, M.R., Morgan, A.J., 1996. The use of enzymes in poultry diets. World's Poult. Sci. J. 52, 61-68.

Bedford, M.R., 2000. Exogenous enzymes in monogastric nutrition-their current value and future benefits. Anim. Feed Sci. Technol. 86, 1-13.

Brenes, A.M.S., Smith, M., Guenter, W., Marquardt, R.R., 1993. Effect of enzyme supplementation on the performance and digestive tract size of broiler chickens fed wheat- and barley-based diets. Poult. Sci. 72, 1731-1739.

Choct, M., Hughes, R.J., Bedford, M.R., 1999. Effects of a xylanase on individual bird variation, starch digestion throughout the intestine, and ileal and ceacal volatile fatty acid production in chickens fed wheat. Br. Poult. Sci. 40, 419-422.

Cowieson, A.J., Hruby, M., Faurschou Isaksen, M., 2005. The effect of conditioning temperature and exogenous xylanase addition on the viscosity of wheatbased diets and the performance of broiler chickens. Br. Poult. Sci. 46, 717-724.

Dale, N., Batal, A., 2009. Ingredient Analysis Table: 2009. Edition. Feedstuffs Reference Issue and Buyers Guide.

Dänicke, S., Jeroch, H., Böttcher, W., Simon, O., 2000. Interactions between dietary fat type and enzyme supplementation in broiler diets with high pentosan contents: effects on precaecal and total tract digestibility of fatty acids, metabolizability of gross energy, digesta viscosity and weights of small intestine. Anim. Feed Sci. Technol. 84, 279-294.

Dusel, G., Kluge, H., Jeroch, H., 1998. Xylanase supplementation of wheat-based rations for broilers: influence of wheat characteristics. J. Appl. Poult. Res. 7, 119-131.

Dunnington, E.A., Siegel, P.B., 1995. Enzyme activity and organ development in newly hatched chicks selected for high or low eight-week body weight. Poult. Sci. 74, 761-770.

Engberg, R.M., Hedeman, M.S., Steenfeldt, S., Jensen, B.B., 2004. Influence of whole wheat and xylanase on broiler performance and microbial composition and activity in the digestive tract. Poult. Sci. 83, 925-938.

Fontes, C.M.G.A., Ponte, P.I.P., Reis, T.C., Soares, M.C., Gama, L.T., Dias, F.M.V., Ferreira, L.M.A., 2004. A family 6 carbohydrate-binding module potentiates the efficiency of a recombinant xylanase used to supplement cereal-based diets for poultry. Br. Poult. Sci. 45, 648-656.

Gao, F., Jiang, Y., Zhou, G.H., Han, Z.K., 2008. The effects of xylanase supplementation on performance, characteristics of the gastrointestinal tract, blood parameters and gut microflora in broilers fed on wheat-based diets. Anim. Feed Sci. Technol. 142, 173-184.

Low, A.G., 1989. Secretory response of the pig gut to non-starch polysaccharides. Anim. Feed Sci. Technol. 23, 55-65.

Marron, L., Bedford, M.R., McCracken, K.J., 2001. The effects of adding xylanase, vitamin C and copper sulphate to wheat-based diets on broiler performance. Br. Poult. Sci. 42, 493-500.

Mourão, J.L., Ponte, P.I.P., Prates, J.A.M., Centeno, M.S.J., Ferreira, L.M.A., Soares, M.A.C., Fontes, C.M.G.A., 2006. Use of $\beta$-glucanases and $\beta$-1,4-xylanases to supplement diets containing alfalfa and rye for laying hens: effects on bird performance and egg quality. J. Appl. Poult. Res. 15, 256-265.

National Research Council, 1994. Nutrient Requirements of Poultry, 9th rev. ed. National Academy of Sciences, Washington, DC.

Nitsan, Z., Benavraham, G., Zoref, Z., Nir, I., 1991. Growth and development of the digestive organs and some enzymes in broiler chicks after hatching. Br. Poult. Sci. 32, 515-523.

Ponte, P.I.P., Ferreira, L.M.A., Soares, M.A.C., Gama, L.T., Fontes, C.M.G.A., 2004. Xylanase inhibitors affect the action of exogenous enzymes used to supplement Triticum durum-based diets for broiler chicks. J. Appl. Poult. Res. 13, 660-666.

Preston, C.M., McCracken, K.J., Bedford, M.R., 2001. Effect of wheat content, fat source and enzyme supplementation on diet metabolisability and broiler performance. Br. Poult. Sci. 42, 625-632. 
Ribeiro, T., Lordelo, M.M., Ponte, P.I., Maçãs, B., Prates, J.A., Aguiar Fontes, M., Falcão, L., Freire, J.P., Ferreira, L.M., Fontes, C.M., 2011. Levels of endogenous $\beta$-glucanase activity in barley affect the efficacy of exogenous enzymes used to supplement barley-based diets for poultry. Poult. Sci. $90,1245-1256$. SAS, 2001. SAS User's Guide: Statistics. Version 8. SAS Institute Inc., Cary, NC.

Steenfeldt, S., Müllertz, A., Fris Jensen, J., 1998. Enzyme supplementation of wheat-based diets for broilers. 1. Effect on growth performance and intestinal viscosity. Anim. Feed Sci. Technol. 75, 27-43.

Wu, Y.B., Ravindran, V., Thomas, D.G., Birtles, M.J., Hendriks, W.H., 2004. Influence of phytase and xylanase, individually or in combination, on performance, apparent metabolizable energy, digestive tract measurements and gut morphology in broilers fed wheat-based diets containing adequate level of phosphorus. Poult. Sci. 45, 76-84. 